cancer suggested predominant increasing neogenesis capillary and provided for the anatomic bases of the cancer spread and BAI.

Presentation of radial growth vessels in pericancer was intracancer neogenetic vessels distributing to the active growth edge of cancer cell and was also an important sign of predicting high metastatic rate. The cancer spread rate in this group patients with radial growth vessels at pericancer was $80 \%$, mainly through hematogenous dissemination. The cancer cells spread along radial growth vessels through incomplete fissure to adjacent lobe. This might be one main cause of cancer relapse after curable resection. The metastatic rate in the patients without radial growth vessels at pericancer was $7.1 \%$ during follow-up. Therefore, it should stress that metastases and recurrence would be prevented and treated with a prediction of bad prognosis for the patients with radial growth vessels at pericancer by BAG. Each 10 cases were treated by radiotherapy and by curable resection separately after BAI. $\mathrm{BAI}$ combined with the resection was better than radiot- herapy alone, but it is necessary to collect more patients for evaluating results.

\section{References}

1. Mountain CF. Revision in the international system for staging lung cancer. Chest, 1997, 111: 1710-1717.

2. Srivastava A, Laidler P, Davies RP, et al. The prognostic significance of tumor vascularity in intermediate-thickness (0.76- $4.0 \mathrm{~mm}$ thick ) skin melanoma: a quantitative histologic study. Am J Pathol, 1988, 133: 419-423.

3. Weidner N, Semple JP, Welch WR, et al. Tumor angiogenesis and metastasis - correlation in invasive breast carcinoma. N Engl J Med, 1991, 324: 1-8.

4. Macchiarini P, Fontanini G, Hardin MJ, et al. Blood vessel invasion by tumor cells predicts recurrence in completely resected T1 No Mo non-small-cell lung cancer. J Thorac Cardiov Surg, 1993, 106: 80-89.

\title{
Solicit for Subscriptions of The Chinese-German Journal of Clinical Oncology
}

The Chinese-German Journal of Clinical Oncology, a medical academic periodical superintended by Chinese Educational Ministry, sponsored by Huazhong University of Science and Technology and cooperatively published by China-Germany, is issued and published as a united journal of Chinese-German Medical Association in China and German-Chinese Medical Association in Germany.

This jounral can be ordered at local post offices of China and also directly subscribed from Editorial Office of The Chinese-German Journal of Clinical Oncology.

Publication on the 25th of the end of each quarter, Code No. BM 38-121

Quarterly issued both internal and external

$$
\begin{array}{r}
\text { Price: Domestic: RMB 28.00 per issue } \\
\text { Overseas: USD 30.00 }
\end{array}
$$

\begin{abstract}
$\Delta$ Bank of Deposit: Hankou Office of Chinese Industrial and Commercial Bank $827948 \Delta$ The Unit of Deposit: Tongji Hospital, Tongji Medical College, Huazhong University of Science and Technology $\Delta$ Accounts: $3202016209000023966 \Delta$ Telephone: 0086-27-83662630 \ Linkman: Wu Qiang A Address: Tongji Hospital,
\end{abstract} No. 1095, Jiefang Dadao, Wuhan 430030, China $\Delta$ Email: dmedizin@ tjh. tjmu. edu.cn 